\title{
a aprendizagem do "estar morto" como estratégia metodológica na pesquisa com crianças
}

\author{
caroline trapp de queiroz ${ }^{1}$ \\ universidade do estado do rio e janeiro, brasil
}

resumo

Este artigo tem por objetivo, de um lado, apresentar uma metodologia maturada, em sua concepção, de forma coletiva, no interior das discussões do Grupo de Pesquisa Infância e Cultura Contemporânea, institucionalmente vinculado ao Programa de Pós-Graduação em Educação da Universidade do Estado do Rio de Janeiro, e explorada, de modo particular, no contexto do campo de uma pesquisa de doutorado. Por outro lado, se propõe conhecer as experiências de deslocamento de crianças que se mudam de residência. O "estar morto", presente no título, se fundamenta no conto do escritor italiano Ítalo Calvino que traz, na reflexão de Palomar, um personagem literário cuja vida é marcada pelo modo singular com que enxerga o mundo, ou seja, a possibilidade da criação de uma perspectiva de visada que implica perceber uma realidade na qual sua presença não determina de modo diretivo os rumos das experiências, ainda que implique alteração material no tempo e no espaço vividos. Assim, quando fala sobre aprender a olhar o mundo como quem está morto, Palomar nos provoca a pensar formas de conhecer o outro que demandam um observar não isento e que, por isso mesmo, não desresponsabiliza o pesquisador da relação que com seus interlocutores estabelece. Passam a compor nossas questões, então, as seguintes reflexões: quando a criança atrai nosso olhar no cotidiano de um tempo marcado pela aceleração, em que olhar para o outro tornou-se perda, seja de tempo, seja de dinheiro, seja da ética que preconiza considerar o outro nas decisões que tomamos individualmente? Como a infância se mostra para nós no movimento da vida? O que é possível que ela nos diga, ainda que a proposta seja adiar a interlocução direta, demorando-se na observação que, mediada pelo que nos afeta, também provoca um movimento dialógico?

palavras-chave: educação; pesquisa com crianças; estudos da infância.

\section{el aprendizaje de "estar muerto" como estrategia metodológica en la investigación con niños}

resumen

Este artículo tiene por objetivo presentar, por un lado, una metodología que fue madurando de forma colectiva dentro de las discusiones acontecidas en el Grupo de Investigación Infancia y Cultura Contemporánea, vinculado al Programa de Post-grado en Educación de la Universidad del Estado de Río de Janeiro y explorada, particularmente, en el contexto de una investigación de doctorado. Por otro lado, se propone conocer las experiencias de niños que se mudan de residencia. El "estar muerto", presente en el título, encuentra su origen en el cuento del escritor Ítalo Calvino que trae, en la reflexión de Palomar - personaje literario cuya vida es marcada por el modo singular en que ve el mundo -, la posibilidad de creación de una perspectiva que implica percibir una realidad en la cual su presencia no determina de modo direccionante los rumbos de las experiencias, aunque eso implique la alteración material en el tiempo y el espacio vividos. De este modo, cuando habla sobre aprender a mirar el mundo como quien está muerto, Palomar nos invita a pensar formas de conocer al otro que demandan una mirada que no está exenta y que, por tanto, no exime de responsabilidad al investigador con respecto a la relación que establece con sus

${ }^{1}$ E-mail: trapp.queiroz@gmail.com 
a aprendizagem do "estar morto" como estratégia metodológica na pesquisa com crianças

interlocutores. Pasan a componer nuestras cuestiones, las siguientes reflexiones: cuando el niño atrae nuestra mirada en la cotidianeidad de un tiempo marcado por la aceleración, en la que la mirada hacia el otro se volvió pérdida de tiempo, de dinero o de la ética que preconiza considerar al otro en las decisiones que tomamos individualmente? Cómo se nos muestra la infancia en el movimiento de la vida? Qué es posible que ella nos diga, aun cuando la propuesta sea postergar una interlocución directa, demorándose en la observación que, mediada por lo que nos afecta, también provoca un movimiento dialógico?

palabras clave: educación; investigación con niños; estudios de la infancia.

\section{the learning of "to be dead" as a methodological strategy in research with children}

abstract

This article aims to present a methodology developed collectively within the discussions of the "Childhood and Contemporary Culture Research Group", institutionally linked to the Postgraduate Program in Education of the State University of Rio de Janeiro and explored in a particular way - in the context of a doctoral research field. In addition, it proposes to know about the experiences of displacement of children who move to a new residence. The expression "to be dead" in the title is based on Italo Calvino' s tale that brings forth, in Palomar's reflection - a literary character whose life is marked by the singular way in which he sees the world -, the possibility of creating a perspective of seeing that implies perceiving a reality in which one's presence does not determine in a directive way the course of the experiences, although it implies a material change in the lived time and space. Thus, when he talks about learning to look at the world as someone who is dead, Palomar provokes us to think of ways of getting to know others which demand a not exempt observation and therefore does not disclaims responsibility from the researcher of the relationship that he establishes with his interlocutors. The following reflections come to compose our questions: When the child attracts our gaze in the quotidian of a time marked by acceleration, in which to look at others has become loss, be it of time, money or ethics that advocates considering others in the decisions we make individually? How does childhood show itself to us in the movement of life? What is it possible for it to tell us, even if the proposal is to postpone direct interlocution, lingering in the observation that, mediated by what affects us, it also provokes a dialogical movement?

keywords: methodology; research with children; ethics. 
a aprendizagem do "estar morto" como estratégia metodológica na pesquisa com crianças

\section{buscando novas formas de pesquisar a infância}

As discussões articuladas nesse texto nascem das reflexões, ainda embrionárias, empreendidas no interior do movimento de construção da pesquisa coletiva do Grupo de Pesquisa Infância e Cultura Contemporânea (GPICC) da Universidade do Estado do Rio de Janeiro (UERJ), e encontram nos movimentos iniciais de minha pesquisa de doutorado a dimensão entrelaçadora de ciência e vida. Assim, uma ideia até então mobilizada a partir de uma maturação teórica, se desenrola no campo vívido da pesquisa.

Tudo começa com o desafio de pensar outras metodologias de pesquisa com crianças, balizadas pela necessidade de, junto delas, pensar também formas de registro que deem conta do percurso que se quer construir, o de enxergar o que aparece de uma infância que cruza conosco nos caminhos da vida cotidiana. Esse desafio estremece, de certa forma, as estruturas em que alicerçamos, ao longo de mais de dez anos, os presumidos e pactuados no interior do Grupo. Esse estremecer foi sentido a princípio a partir da resistência característica de um movimento que demanda abrir mão do que sabíamos e nos lançar ao escuro, tateando em busca de elementos que nos devolvessem a segurança típica dos que, mesmo em meio à ludicidade de um "gato mia", 2 experienciam o alívio de tocar mãos, cabelos e outras partes corpóreas compositoras de um todo - o outro - que nos é familiar.

O deliberado roubo do chão em que assentávamos nossas certezas foi uma estratégia importante na tomada de decisão sobre esse aventurar-se nas sendas de uma reflexão e descoberta de outras formas de realizar pesquisas com crianças. Talvez, seja importante destacar que, para nós, que temos na teorização quanto à ética na pesquisa com crianças um eixo-chave de trabalho, essa perspectiva metodológica de fato implicou - está implicando! - colocar em xeque muitas questões já assentadas em nosso horizonte de constituição teórico-filosófica.

Assim, passado o susto inicial da proposta, começamos a pensar que caminhos eram possíveis e desejáveis para nós. Que leituras nos auxiliariam a repensar a pesquisa, o pesquisador, a relação com os interlocutores, em especial esses nossos, as crianças? Que formas de registro do campo responderiam ao objetivo de tentar conhecer uma infância que se revela para nós justamente porque aparece quando apreende ou captura nosso olhar, e não necessariamente quando forjamos modos de com ela estar? Que tratamento dispensar a essas "fontes"? Essas reflexões todas têm lançado luz às nossas questões e encontram-se em vias de maturação, de estudo e discussão, o que significa dizer que o teor desse artigo se situa no "enquanto" de processos ainda em desenvolvimento.

O que decidimos até então foi abrir mão de uma situação de pesquisa que ganhasse vida a partir da nossa convocação, ou seja, passou a nos interessar contextos instaurados pela dinâmica da própria vida que, por conta do afetamento,

\footnotetext{
2 Brincadeira realizada em ambiente escuro em que, vendada, uma pessoa deve procurar, tateando o espaço, pelas outras, que lhe provocarão movimentando-se a todo momento, tentando confundir - e angustiar - a "caçadora". Ao conseguir capturar alguém, a pessoa vendada deve descobrir de quem se trata a partir da identificação do "miado" emitido no momento.
} 
a aprendizagem do "estar morto" como estratégia metodológica na pesquisa com crianças

nos provoquem a observar e pensar a infância. Quando a criança atrai nosso olhar no cotidiano de um tempo marcado pela aceleração, em que olhar para o outro tornouse perda, seja de tempo, seja de dinheiro, seja da ética que preconiza considerar o outro nas decisões que tomamos individualmente? Como a infância se mostra para nós no movimento da vida? O que é possível que ela nos diga, ainda que a proposta seja adiar a interlocução direta, demorando-se na observação que, mediada pelo que nos afeta, também provoca um movimento dialógico?

Essa percepção, que permite compreender o diálogo como um movimento que não depende necessariamente de interlocução, mas sim de abertura ao outro e aos modos como ele pode nos afetar, implica compreender que os pesquisadores ocupam o lugar de tradutores daquilo que observam. É importante perceber que esse é um lugar que o pesquisador ocupa em pesquisas que se valham de qualquer percurso metodológico, nas ciências humanas, mas que ganha mais destaque em metodologias de observação do cotidiano, justamente porque descortina que a assunção do lugar de sujeito sócio-histórico de direitos e o balizamento da ética de pesquisa não dependem da abertura da fala, mas sim da consciência. Eu só aceitarei o outro e com ele me porei em relação dialógica a partir da reflexão sobre o que, como pesquisador, "devo" fazer num contexto de relação de poder que marca a singularidade da pesquisa.

Questionar-se sobre o que "devo" fazer em relação ao outro "implica simultaneamente o posicionamento ativo do sujeito e o reconhecimento da dimensão social da sua ação, sem os quais a própria ideia de ética se torna esgarçada" (BORHEIM apud PEREIRA, 2015 p. 55). Pereira (2015) destaca que, nas pesquisas acadêmicas, essa pergunta vem sendo substituída pela que indaga "o que posso fazer?", uma pergunta de cunho mais protocolar, que parece delimitar as ações diante dos sujeitos com quem estabelecemos a relação de pesquisa, conferindo, dessa forma, a sensação de que o processo está eticamente garantido, liberando-nos, enquanto pesquisadores, de responder e nos responsabilizar pelos imponderáveis que, na dinâmica da vida e da pesquisa, estão sempre postos. Nesse sentido, quando a normativa se sobrepõe à indagação contínua sobre que postura baliza nossa ação diante do outro, acaba-se por expropriar os sujeitos envolvidos "do lugar social que poderiam ocupar na construção de uma ética de pesquisa e na responsabilidade pela ciência que produzem" (PEREIRA, 2015, p. 55).

Essa reflexão é importante porque dela nasce a postura com a qual esse outro será enxergado, recebido, tratado e apresentado no texto - lembrando que as ciências humanas são ciências do texto, pois têm como meio de divulgação a circulação escrita de procedimentos de pesquisas, sendo o texto aqui entendido como o ato de comunicar, que une palavra e enunciado, signo e sentido (BAKHTIN, 2011). E essa postura, quer queira o pesquisador ou não, aparece impressa no texto, numa cristalização da ética que balizou o processo todo, desde a elaboração das questões, das escolhas metodológicas, até o encontro com o outro e os modos como escolheu-se traze-lo na narrativa científica.

Assim, em meio à busca por modos de pesquisar que, mediante nossas discussões metodológicas no interior do Grupo, pudessem dialogar com os projetos realizados individualmente por cada pesquisador, fomos traçando nosso percurso em torno de concepções de pesquisa, de conhecimento, de verdade e de infância, concepções que fundamentam, nesse momento inicial, cada nova escolha que fazemos. 


\section{como "estar morto"}

Esse movimento de reflexão e busca por referenciais que nos ajudem a repensar nossas questões de pesquisa nos levou à leitura do livro Palomar, último livro que Italo Calvino publicou em vida. A proposta era tecer laços entre a arte, na linguagem poética de Calvino, e a ciência, na construção desse modo outro de fazer nossas pesquisas. É precisamente do imbricamento de ciência, arte e vida, ao qual nos convoca Bakhtin (2011), que o despertar à literatura como caminho metodológico de leitura do social se tornou possível para nós enquanto potência de reflexão. $\mathrm{O}$ autor nos chama atenção ao fato de que a arte existe justamente porque a vida não basta. Sendo assim, separar ambas as dimensões implica eximir-se de responsabilidade, afinal, "é mais fácil criar sem responder pela vida" (BAKHTIN, 2011, p. XXXIII), num modelo artístico cartesiano e produtivista, "e mais fácil viver sem contar com a arte" (Idem), desconectando-se do âmbito da estética, da aisthesis palavra usada pelos gregos para se referir a sensações, em geral, ou à capacidade de perceber (TIBURI, s.d.).

Como esses três campos da cultura humana, ciência, arte e vida, "só adquirem unidade no indivíduo que os incorpora à sua própria unidade" (BAKHTIN, 2011, p. XXXIII), partimos à assunção desse entrelaçamento, buscando ocupar o lugar de quem encontra e defende, na estética literária, a existência de dispositivos metodológicos e afetivos de leitura da realidade. É nesse movimento que se situa a aproximação com a obra de Calvino. Nela, Palomar é um senhor que olha para o mundo num belo entrecruzamento de leveza e profundidade. O cotidiano alimenta seu pensamento, que vai se desenrolando a partir do que lhe aparece. Nesse sentido, Palomar não busca o que vê, mas vê o que se mostra a seu olhar: um olhar atento, de quem se posiciona em abertura e curiosidade, de quem se deixa ser arrebatado pelo trivial e ordinário. $\mathrm{Na}$ orelha do livro encontramos a seguinte narrativa sobre Palomar:

Palomar é o nome de um famoso observatório astronômico que durante muito tempo ostentou o maior telescópio do mundo. Por intencional ironia, é também o nome do protagonista destes textos curtos de Italo Calvino, pois este senhor Palomar é todo olhos, mas funciona quase sempre como se fosse um telescópio ao contrário, voltado não para a amplidão do espaço, mas para as coisas próximas do cotidiano. É como se ele nos dissesse que as grandes questões do mundo e da existência também estão presentes em cada objeto que observamos, em cada cena que presenciamos, e que tudo é digno de ser interrogado e pensado (CALVINO, 1994, orelha do livro).

Pensar as grandes questões do mundo e da existência a partir das cenas que presenciamos, considerando que tudo é digno de ser interrogado. Essa passou a ser a premissa do nosso olhar para as crianças, essas com quem não conversamos cotidianamente, que não conhecemos intimamente, mas que nos deslocam, nos inquietam, nos roubam das certezas, seja pelo motivo que for, e nos lançam num abismo geralmente temido pelos pesquisadores: o de tomar consciência de que pouco (ou nada) se sabe sobre os sujeitos com quem se pesquisa. Abismo esse que, se desesperador do ponto de vista da efemeridade do que é o elemento humano e da necessidade que é "deter" o conhecimento, ao ocupar o lugar de quem se pressupõe 
a aprendizagem do "estar morto" como estratégia metodológica na pesquisa com crianças

que saiba de algo, por outro lado nos chama à esperança da construção de uma compreensão que necessita justamente do inacabamento desse "não saber" para que se torne, então, algo a ser descoberto.

A leitura desses contos nos ajudou muito a pensar as potencialidades expressas no cotidiano e a necessidade de reeducar nosso olhar para enxergar o que aparece, o que nos convida a demorar mais nos detalhes, a suspender o tempo da correria, dos prazos, da ansiedade, e dar ao tempo, tempo de se tornar significativo, de emergir como questão, como provocação. Dentre esses contos, um se destacou como eixo de reflexão sobre possíveis modos de se fazer pesquisa: "Como aprender a estar morto" (CALVINO, 1994, p. 108).

O que o senhor Palomar tenta nos elucidar nesse conto é como se colocar no lugar de quem observa, sem intervir de acordo com propósitos pré-estabelecidos. Nessa ideia há uma sensível distinção entre morrer e "estar morto", pois se morrer implica um não estar mais presente e, portanto, não existir na equação das experiências mundanas, "estar morto" pressupõe "estar", de modo que o que acontece, acontece numa composição que considera essa minha existência, ainda que eu esteja buscando, nesse "estar", um "estar morto". Se ao morrer, não estou mais presente, ao tentar "estar morto", eu me encontro presente no mundo, mas em estado de quietude, não-intervencionista, numa tentativa de não influência que é, obviamente, filosófica e abstrata,

\begin{abstract}
Antes, por mundo ele entendia o mundo mais ele; agora se trata dele mais o mundo sem ele. $\mathrm{O}$ mundo sem ele significará para ele o fim da ansiedade? Um mundo em que as coisas acontecem independentemente de sua presença e de suas reações, seguindo uma lei ou necessidade ou razão própria que não diz respeito a ele? (CALVINO, 1994, p. 109).
\end{abstract}

A partir desses questionamentos, o senhor Palomar chega à reflexão de que esse "estar morto" é um estado de não presença ativa. Embora eu esteja presente e, portanto, em posição ativa no mundo, não influencio as experiências justamente porque tento observa-las como se não estivesse ali. Desdobrando esse movimento para o contexto da pesquisa, o lugar desse "estar morto" é precisamente aquele ocupado pelo pesquisador que não tem - e não pretende ter - ação propositiva no campo, ou seja, o pesquisador que não dá as cartas do jogo, mas que se propõe a reaprender a olhar o outro a partir daquilo que ele lhe mostra.

Duas coisas devem estar claras nesse momento: a primeira delas, é que esse percurso metodológico não se trata da busca pela isenção do pesquisador, num modelo asséptico de ciências humanas que, em especial no século XIX, aspirava à neutralidade e à imparcialidade. Dessa forma, "estar morto" não desresponsabiliza o pesquisador do conhecimento que ele constrói, pelo contrário, sendo ele um tradutor daquilo que vê e autor da reflexão que propõe, a assinatura teórica e metodológica é compromisso seu, e por isso ele deve responder integralmente. Mesmo diante das apropriações feitas, as construções todas são decisões de cunho ético, pois assinar um pensamento é torna-lo ato seu no texto de sua autoria (BAKHTIN, 2010).

A segunda questão que deve ser esclarecida quanto ao "estar morto" diz respeito à ideia de que não há nada nesse movimento que implique anestesiar-se diante do outro. A premissa de que o pesquisador não pode se envolver com os 
sujeitos que pesquisa advém exatamente desse sentido de assepsia das ciências humanas de moldes positivistas e racionalistas, em que o pesquisador é alguém que, para alcançar distanciamento e profundidade reflexiva, deve manter distanciamento psíquico e emocional quanto aos sujeitos de seu campo de pesquisa. O "estar morto" não sugere, portanto, um apagar-se do campo para sobre ele pensar, pelo contrário, do modo como temos concebido esse movimento, entendemos que só é possível observar algo quando nos permitimos à abertura a esses outros que dividem conosco a construção de uma pesquisa, e essa abertura pressupõe receber o que se lança ao olhar, enxergar o que aparece, afetar-se mesmo que esse afeto nos fira de alguma forma.

O "estar morto" tem nos guiado, portanto, como um horizonte de pesquisa, mas um horizonte que, sabemos, é utópico,

A utopia está lá no horizonte. Me aproximo dois passos, ela se afasta dois passos. Caminho dez passos e o horizonte corre dez passos. Por mais que eu caminhe, jamais alcançarei. Para que serve a utopia? Serve para isso: para que eu não deixe de caminhar. (BIRRI apud GALEANO, 1994, s.p.)

Entendendo que esse "estar morto" é uma motivação à abertura ao que o outro nos apresenta de si quando cessamos as perguntas e nos demoramos na observação, nos convencemos de que se trata de um estado que serve para nos manter em movimento, para nos retirar da inércia dos conhecimentos já sabidos, seguros que estão - embora não devessem - dos questionamentos, desses modos de fazer que, repetindo-se à exaustão, acabam ganhando tons de produção metodológica mecânica e, nesse processo, quase que nos liberando da tão necessária reflexão quanto à ética que nos mobiliza, como pesquisadores, a escolher esse ou aquele caminho, esse ou aquele contexto, esse ou aquele sujeito, esse ou aquele teórico.

"Estar morto", antes de nos liberar do ato responsável em pesquisa (BAKHTIN, 2010), reitera que a responsabilidade é sempre nossa, porque é sempre escolha, ou seja, não há álibi ${ }^{3}$ para os modos como colocamos a pesquisa nos trilhos, muito porque quem determina que trilhos são esses somos nós. Não há desculpas!

\section{da construção e viabilização de um campo de pesquisa sob o pressuposto de "estar morto"}

Conforme mencionei no início desse artigo, as reflexões quanto à construção de outros percursos metodológicos vão emergindo também no processo de pesquisa que desenvolvo a nível de doutorado. Nela, tenho como objetivo investigar as experiências de crianças que se mudam de residência, tentando apreender que afetos estão postos nessas transitoriedades. A ideia é pensar as relações tecidas pelas crianças com os processos de deslocamento vividos, com o ato de mover-se, bem

\footnotetext{
3 Ponzio (2010, p. 20) destaca que o "não-álibi", em Bakhtin, significa "sem desculpas", "sem escapatórias", mas também "impossibilidade de estar em outro lugar" em relação ao lugar único e singular que ocupo no existir, existindo, vivendo.
} 
a aprendizagem do "estar morto" como estratégia metodológica na pesquisa com crianças

como com os pontos de partida e chegada, expressos na figura da casa - que ganha contornos muitos distintos, de acordo com o contexto.

Uma primeira coisa que vai ficando clara na chegada a esse tema é que, independente dos motivos que levem à mudança, uma questão é fundamental de se ter em vista: estamos falando de pessoas. Mudar não é apenas ir de um lugar para o outro, mas levar consigo o solo de onde veio, as relações tecidas ali, os afetos construídos, os significados partilhados... e, da mesma forma, projetar a vida sob um novo horizonte, adornado pelo medo do desconhecido, dos tais novos "amiguinhos", quando quem se muda é a criança, do medo da escola, de não ser aceito. Mudar é um constante repensar sobre quem sou eu, aqui e agora, e sobre o que faz sentido nessa construção da subjetivação - entendida como a construção que ocorre a partir dos encontros que vivemos com o outro e com o mundo, uma construção social, portanto. Essa dimensão de humanidade ajuda a dar rostos aos números levantados em relação às migrações internas e externas - tema em alta contemporaneamente, muito por conta dos conflitos envolvendo pessoas em situação de refúgio -, pois desnuda que, por traz de cada cifra, há uma história a ser contada.

Diante da perspectiva de conhecer os afetos postos nos deslocamentos infantis, nesses contextos de mudança de residência, parti para a escolha de um caminho metodológico que fizesse sentido, pensando que todo o tema traz consigo o germe de um "como fazer" que lhe é específico. Assim, na tentativa de fazer brotar um campo significativo, encontrei na estética da escrita fragmentária de Walter Benjamin ${ }^{4}$ pista e inspiração para pensar que não se une forma e conteúdo, pois isso faz nascer algo novo, um terceiro elemento. Na verdade, o entrelaçamento de forma e conteúdo só se dá, de fato, quando ambos nascem imbricados, um no outro. Foi pensando sobre esse imbricamento, e mobilizada pela reflexão sobre a busca de "estar morto", que a metodologia do campo de minha pesquisa foi capturada pelo olhar que tanto lhe buscava: o momento de fechar e abrir as caixas da mudança.

Quando criança, me mudei de casa repetidas vezes, e sempre tive no fechamento das caixas um momento importante de reflexão sobre todo o processo - e a vida. Pensando sobre a potência desse momento, que mobiliza afetos, memórias, histórias e expectativas, elegi como caminho metodológico estar junto das crianças, fechando e abrindo suas caixas. No entanto, diante dessa escolha, muitos desafios foram se descortinando, na corrente de quem pensava, coletivamente, um outro modo de movimentar as decisões metodológicas: como "estar morta" num campo que pressupõe estar fechando ou abrindo caixas de mudança com a criança? Como acessar esse tempo e espaço tão íntimos, estar na casa da criança, mexendo em suas coisas, sem que minha presença atue propositivamente - ou mesmo incomode? Como atrelar à interlocução necessária com a criança nesse processo, a observação de seus movimentos, de seus afetamentos? Como encontrar ou saber qual o equilíbrio entre o que existe para ser observado e o que necessita de uma construção narrativa, da troca dialogada?

\footnotetext{
4 Essa estética marca o movimento que o filósofo empreende durante sua vida em direção a um modelo de escrita de fragmentos, respeitando e se constituindo no interior das mudanças tecnológicas de seu momento histórico, quando surgem os reclames, os outdoors e toda uma concepção de escrita que precisa comunicar de modo breve. Essa trajetória culmina, para Benjamin, na realização da obra inacabada das "Passagens", escrita de 1927 a 1940 e publicada pela primeira vez em 1982, onde essa estética se faz marcadamente presente.
} 
Esses questionamentos se potencializam, na dinâmica da vida e no interior de uma conversa informal com uma amiga, quando surge a primeira possibilidade de estar em campo, sem qualquer preparação prévia, para participar do processo de fechamento das caixas com uma menina de dez anos, a Antônia, que se preparava para mudar de casa, na cidade de Nova Friburgo, no Estado do Rio de Janeiro. O processo de mudança da Antônia consistia em sair de uma casa, grande e espaçosa, com um belo quintal que abrigava pés de laranja e manjericão, bonitos hibiscos vermelhos e estrelícias alaranjadas, além de seus dois cachorros, Nina e Chocolate, para um apartamento com metragem menor que a da casa, num condomínio com ampla área de lazer, com piscina, quadra de esportes, churrasqueira e salão de jogos.

E assim, "no meio do caminho", quase sem querer, teve início o campo de minha pesquisa de doutorado. É importante refletir sobre esse "meio de caminho", no interior das ciências humanas, justamente porque ele nos salva da ilusão de uma pesquisa limpa, cronológica e asséptica. Em tese que buscou refletir sobre o intervalo existente entre o projeto e o trajeto da criação em Arte, Pohlmann $(2005$, p. 6) afirma que o encontro entre o tempo da criação e o tempo cronológico que guia nosso cotidiano - na sociedade ocidental industrializada -, dá início a outra coisa, uma coisa que ela belamente narra como sendo específica da criação artística, mas na qual enxergo inscrita a trajetória da pesquisa, do modo como está sendo pensada aqui,

A poética do ato criador dá-se nesta tensão entre o processo e o instante. Os instantes criadores, esses momentos de formulações novas oferecidas pelo pensamento são encontrados no meio do percurso, no meio-do-caminho. Quando nos sentimos no meio do caminho, não estamos nem lá nem cá. Estamos em trânsito, em transformação, num ponto do tempo/espaço intermediário. Tentamos perceber condensando o que antes estava disperso. Passado e presente se superpõem, num movimento aparente e sem imagens fixas. Interessa-me particularmente o vai-e-vem imbricado no instante e no fugaz, na intensidade como fruição e nas impressões internas que irrompem pela sensibilidade. Por outro lado, tal como uma força que dinamiza a matéria e muda seus contornos e constituição, o tempo se faz visível na permanente modificação de formas da materialidade das coisas. Percorremos terrenos, desertos, pântanos, penhascos e abismos. Andamos para frente, para trás, e às vezes em círculos. Nossas pegadas formam um desenho que inclui não só a nossa passagem, mas também as marcas deixadas pelo tempo. Seu movimento se faz pela contínua transfiguração em trânsito. Não há um mapa traçado previamente que nos indique o melhor caminho a seguir. Nem mesmo um itinerário pré-estabelecido que possa nos guiar sem que os desvios e as curvas sinuosas apareçam no meio desta travessia. Este é um caminho que está para ser inventado de maneira singular, e não há como evitar as incertezas que dele fazem parte.

O meio-do-caminho a que se refere a autora constitui, então, uma espécie de limbo, pensando na figura do pesquisador, pois não se está nem lá nem cá, ao mesmo tempo em que se ocupa e se vive este lugar por inteiro, na medida em que os processos de pesquisa vão se apresentando ao seu entendimento. Nesse intermediário reside a dúvida, a apreensão, a incerteza, a inquietude, mas, da mesma 
a aprendizagem do "estar morto" como estratégia metodológica na pesquisa com crianças

forma, é nesse limiar que as possibilidades se abrem como perspectivas prováveis, como caminhos existentes, como expectativa e esperança de um jeito outro de compreensão. O meio do caminho é o momento em que as decisões tomadas constroem o percurso pelo qual se andará - ao mesmo tempo em que por ele já se começa a dar os primeiros passos.

Passada a surpresa, aceitei o convite e, no dia seguinte, fui para Nova Friburgo acompanhar o fechamento das caixas com Antônia, que sequer suspeitava sobre minha ida. Quando nos encontramos, eu me lembrava da menina pequena e com feições mais infantis que havia conhecido três anos antes. Ela, por sua vez, não se lembrava de mim, algo que percebo ser muito comum com as crianças e que relaciono aos modos com que elas tecem suas significações temporais, e isso é o mesmo que dizer que o tempo para os adultos transcorre de modo diferente que para as crianças - considerando a heterogeneidade dos grupos sociais e levando em conta que também existem especificidades temporais que variam subjetivamente, de pessoa para pessoa. Em outras palavras, o tempo não é uma ou duas coisas só, e no meu encontro com Antônia fica claro que meu tempo de rememoração sobre quem ela é se difere do tempo de rememoração dela sobre quem seria eu.

Nossa relação foi se construindo sem pressa, sem força, mas envolta num processo de troca bastante interessante: de minha parte porque eu estava ali ajudando a encaixotar as coisas da mudança, mas também atenta aos movimentos, diálogos, olhares e gestos que se teciam e apareciam durante esse momento, e todos sabiam disso; da parte de Antônia porque sabia que somente a sua presença naquele tempo e espaço poderia me dar esse "algo" pelo qual eu ali estava, finalmente tornando meu intento de pesquisa um acontecimento (PEREIRA, 2012, p. 42). Sei que Antônia toma consciência e se apropria do importante lugar que ocupa na pesquisa justamente porque é ela quem me convida a ajudá-la a "fechar as caixas" de seu quarto.

Diante de um campo tão intimista e ao mesmo tempo dinâmico, o caminho da observação passou a fazer sentido também em relação à minha pesquisa de doutorado. Claro que a interlocução não é só uma realidade, mas uma necessidade num campo desenhado por narrativas que vão compondo o tecido da vida, ali revisitado no manuseio de tantos objetos de memória - que, segundo Bosi (2013), se distinguem dos demais justamente pelo lugar que ocupam na constituição da vida de quem os guarda. No entanto, fui percebendo como o olhar atento aos modos de acomodar um quadro na caixa, abraçar uma pelúcia antes de reuni-la ao saco dos brinquedos e mesmo reencontrar meias de lã então perdidas na bagunça que marca o processo de mudança, guarda como potência a capacidade de nos permitir compreender o que se comunica de imediato, sem a demanda por um adorno verbalizado.

Foi também no campo que tive um dos mais belos encontros com o silêncio, que passei a compreender a partir de outro aspecto. Já é lugar-comum em pesquisas na área das ciências humanas a compreensão de que o silêncio também responde, de que ele é um dito. No entanto, esses silêncios, quando estão postos em nossas pesquisas, tendem a nos incomodar muito, e logo somos tentados a, do lugar de pesquisador que precisa da fala de seus interlocutores, preenche-los com palavras. A reflexão metodológica quanto à observação possibilitou, no meu campo em específico, uma espécie de libertação quanto ao preenchimento dos vazios, muito 
porque permitiu compreender o vácuo como espaço de construção de um afeto que é outro e que, por isso mesmo, também diz de algo.

Sobre a busca por "estar morta", entendo que, muito embora a minha presença não intervenha constantemente no campo, isso não significa que eu não esteja presente por inteiro no processo. Nesse sentido, estamos falando, então, na pesquisa que entrelaça observação e interlocução, de uma presença consciente, que sabe estar ali "para" algo, pois tem um objetivo determinado, mas que sabe também dar tempo ao tempo, esperar que as abóboras de ajeitem na caçamba sem necessariamente tentar arruma-las da sua própria maneira a todo custo.

Como já destaquei, esse modo de pesquisa é velho conhecido dos antropólogos, que historicamente desenvolveram seu status científico a partir de uma observação não-propositiva, que tinha por fundamento a isenção e a neutralidade. Isso num modelo que se embasou nos pressupostos das ciências naturais para ser social e academicamente reconhecido como ciência humana. É claro que muito já se discutiu e criou a partir das críticas a esse modelo asséptico, positivista e racionalista de pesquisa. Mas, então, que reflexões esse artigo está desenhando? Seria uma proposta de recuperação do método da observação não-participante?

Entendo que o aspecto ao qual quero chamar atenção aqui reitera o que a antropologia postula metodologicamente, ou seja, a percepção de que a observação é também uma intervenção, mas uma intervenção que ocorre porque nossos corpos são ativos, compondo e decompondo contextos que, sem eles, não se desenhariam da mesma maneira. Nosso horizonte utópico, nesses termos, não se relaciona à assepsia de um "estar presente" com o outro, mas sim à tentativa de nos lançarmos ao mundo, dispostos ao despertar sensível que ele pode - como potência que guarda em si - nos propiciar. Isso é o mesmo que dizer que aprender a "estar morto" é uma busca de não-interferência no sentido da construção de um campo de pesquisa por parte do pesquisador, um campo que nasce da seleção dos tempos e espaços, que opera quase que uma artificialização do real, que tem por objetivo controlar o acontecimento para sobre ele se deter. Fazemos isso o tempo todo!

Essa compreensão é deslocada à área da Educação a partir das propostas dos estudos do cotidiano, que mais e mais se lançam ao mundo com a intenção de conhece-lo melhor nesse processo de "estar sendo" que constitui nossas experiências na vida. É, portanto, no enquanto da experiência humana sobre a Terra, ou mais especificamente, da experiência da criança na cultura, que se encontra a relevância das reflexões aqui propostas. O objetivo não é pensar algo novo, inédito, mas pensar genuinamente outras possibilidades diante do que construímos como ato de pesquisa e passamos, ao longo do tempo, a realizar quase que automaticamente, nos liberando da responsabilidade de pensar que ética nos conduz nesse "fazer" com o outro, no caso, a criança.

Pensar outros modos de fazer é repensar por que estamos fazendo o que fazemos? Por que estudar crianças na relação com a cultura? Qual a implicação daquilo que construímos, dado que ocupamos o lugar de cientistas na realidade social? Para que falar sobre o que falamos? E talvez mais importante que tudo: O que queremos fazer existir a partir do que comunicamos para o mundo com as nossas pesquisas? Esses pensares todos vão constituindo, portanto, o movimento que estamos vivendo, no espaço coletivo do GPICC e também no íntimo de cada um de nós, em nossas pesquisas individuais. E esses são pensares que nos estruturam na ciência e na vida. Não há álibi! 
a aprendizagem do "estar morto" como estratégia metodológica na pesquisa com crianças

\section{(in)conclusões: possibilidades para a pesquisa com crianças}

No tipo de pesquisa que discutimos ao longo desse artigo, a vida está acontecendo e somos nós, enquanto pesquisadores, que chegamos e nos inserimos naquilo que passamos a chamar de campo, mas que os interlocutores seguem chamando de vida, de cotidiano, de experiência. Importa pensar esse lócus como "experiência" justamente porque ela expressa a capacidade de nos deixarmos tocar pelo que acontece. Larrosa (BONDÍA, 2002), nos diz dessa experiência como o que fica, e fica porque significa, porque nos toma, nos envolve e passa a nos constituir. Benjamin (2012), por sua vez, vai também ajudando a pensar a experiência como algo que se torna referência e, por isso, é sempre singular. Daí que os autores nos permitam compreender a experiência como algo que toca, mobiliza, passa e acontece, mas sempre no plano da subjetividade. Você fala de dentro de si, fala do que te implica e te convoca. Fala de dentro da sua história...

Entendendo as ciências humanas como ciências de sujeitos que se encontram e se expressam, conforme explica Bakhtin (2011), ou seja, ciências que envolvem ao menos duas pessoas, o pesquisador e o pesquisado, é justo e coerente pensar que o diálogo está posto, independente de onde se realizará o campo. Isso estabelece que a pesquisa é uma ciência relacional e que o pesquisador é um ser no campo, lá no acontecimento, no tempo e no espaço da pesquisa, situado ao lado do sujeito que pretende conhecer, o que determina que sua simples presença já soma, à equação do contexto, um elemento que lhe afeta diretamente - mesmo sendo esse contexto o cotidiano da própria vida, e não um espaço planejado e organizado pelo pesquisador. Ou seja, mesmo na relação de pesquisa em que quem se insere no campo é o pesquisador, não há possibilidade de neutralidade ou isenção, pois ele não está livre do afeto, do afetamento, e isso é um fato, ainda que queira aprender a "estar morto", como estratégia de observação de uma realidade na qual pretende não agir propositivamente.

Toda a pesquisa feita com pessoas é intervenção na medida em que institui que o pesquisador olha e é olhado de volta pelo seu interlocutor, o que pressupõe que o movimento da pesquisa altera ambos os sujeitos que estão em relação. O que se configura desafiador, portanto, é justamente a compreensão de que, para efetivar uma pesquisa pautada no "estar morto", é preciso que, antes de uma inércia garantidora de isenção, o pesquisador assuma o compromisso de buscar outros modos de estar com o outro, o que implica o ato de engendrar seu próprio deslocamento em direção a ele, um deslocamento que vai lhe inserir no cotidiano e na dinâmica da vida do sujeito que ele pretende conhecer, isso num tempo e num espaço sobre os quais esse pesquisador carece de controle.

O movimento que nasce dessa inversão de posições instaura um desenrolar de processos e uma potência de reflexões distintas do campo que é preparado previamente, quase que seguindo a lógica de uma gestação, em que ética e esteticamente pensamos como tornar o espaço propício e acolhedor aos sujeitos que ali chegarão, que estratégias criar para instaurar o diálogo, a dinâmica e a reflexão desejadas. Essa espécie de "pré-campo", que demarca o cuidado do pesquisador em relação aos outros com quem dialogará e também em relação aos recursos de que disporá para dar vida ao encontro, inexiste na pesquisa que se quer cotidiana, muito 
porque o que se prepara não é o tempo e o espaço do encontro, mas tão somente o espírito com que para ele se chegará. ${ }^{5}$

Assim, os sentidos de um aprender a "estar morto" estão permeados pela tentativa de desconfiar de nossas certezas, buscando no calar uma forma de melhor ver e ouvir o outro, sobre o qual muitas vezes construímos presumidos nos quais acreditamos piamente. É justamente o sacudir das convicções que devemos perseguir enquanto pesquisadores, muito porque, quando as certezas se assentam, a reflexão cessa, pois cessam as provocações, as tensões, os questionamentos. Tornar-se sensível ao que escapa e desloca é, portanto, um dos caminhos possíveis de se escolher para viver a pesquisa e o campo como experiência, deixando-nos afetas pelo que acontece. Nesse sentido, o imbricamento entre ciência e vida é uma flexão realizada pelo nosso olhar, pesquisadores desejosos de transitar de forma mais livre, embora responsável, entre tais dimensões. Um campo em plena expansão, portanto, ao mesmo passo que em plena demanda por referenciais teóricos sólidos.

\section{referências}

BAKHTIN, Mikhail. Para uma filosofia do ato. São Carlos: Pedro e João Editores, 2010. . Mikhail. Estética da criação verbal. São Paulo: Martins Fontes, 2011. . Mikhail. Para uma filosofia do ato. São Carlos: Pedro e João Editores, 2010.

BENJAMIN, Walter. Passagens. Belo Horizonte/São Paulo: Editora UFMG/Imprensa Oficial do Estado de São Paulo, 2006.

Walter. Magia e técnica, arte e política: ensaios sobre literatura e história da cultura. São Paulo: Brasiliense, 2012.

BONDÍA, Jorge Larrosa. Notas sobre a experiência e o saber de experiência. Revista Brasileira de Educação. n. 19, Campinas: Unicamp, 2002.

BOSI, Ecléa. O tempo vivo da memória: Ensaios de Psicologia Social. São Paulo: Ateliê Editorial, 2013.

CALVINO, Italo. Palomar. São Paulo: Companhia das Letras, 1994.

GALEANO, Eduardo. Las palabras andantes. Buenos Aires: Siglo XXI, 1994.

PEREIRA, Rita Marisa Ribes; MACEDO, Nélia Mara Rezende (Orgs.). Infância em Pesquisa. Rio de Janeiro: NAU, 2012.

PEREIRA, Rita Marisa Ribes. Por uma ética da responsividade: exposição de princípios para a pesquisa com crianças. Currículo sem Fronteiras, v. 15, n. 1, p. 50-64, jan./abr. 2015.

POHLMANN, Angela Raffin. Pontos de Passagem: o tempo no processo de criação. Tese (Doutorado em Educação). Faculdade de Educação. Universidade Federal do Rio Grande do Sul, 2005.

PONZIO, Augusto. A concepção bakhtiniana do ato como dar um passo. In: TIBURI, Márcia. $\mathrm{O}$ que é sensibilidade? Arte e Filosofia. Disponível em: <http://www.marciatiburi.com.br/textos/sensibilidade.htm>. Acesso em: 26 ago. 2018.

recebido em: 13.07.2018 aceito em: 28.08.2018

\footnotetext{
${ }^{5}$ É importante destacar que as pesquisas que abarcam esse "pré-campo" também demandam a preparação do espírito para se relacionar com o outro, mas não têm nessa a única preparação possível.
} 